\title{
Oral administration of veratric acid, a constituent of vegetables and fruits, prevents cardiovascular remodelling in hypertensive rats: a functional evaluation
}

\author{
Murugesan Saravanakumar ${ }^{1,2}$, Boobalan Raja ${ }^{2 *}$, Jeganathan Manivannan ${ }^{2,3}$, Thangarasu Silambarasan ${ }^{2}$, \\ Pichavaram Prahalathan ${ }^{2}$, Subramanian Kumar $^{2}$ and Santosh Kumar Mishra ${ }^{4}$ \\ ${ }^{1}$ Department of Physiology, College of Medicine, University of Arizona Health Sciences Center, Tucson, AZ 85724, USA \\ ${ }^{2}$ Cardiovascular Biology Lab, Department of Biochemistry and Biotechnology, Faculty of Science, Annamalai University, \\ Annamalainagar, Tamil Nadu 608002, India \\ ${ }^{3}$ Vascular Biology Lab, AU-KBC Research Centre, Anna University, Chennai, Tamil Nadu 600044, India \\ ${ }^{4}$ Division of Pharmacology and Toxicology, Indian Veterinary Research Institute, Izatnagar, Uttar Pradesh 243122, India \\ (Submitted 16 March 2015 - Final revision received 8 June 2015 - Accepted 16 July 2015 - First published online 8 September 2015)
}

\section{Abstract}

In our previous studies, veratric acid (VA) shows beneficial effect on hypertension and its associated dyslipidaemia. In continuation, this study was designed to investigate the effect of VA, one of the major benzoic acid derivatives from vegetables and fruits, on cardiovascular remodelling in hypertensive rats, primarily assessed by functional studies using Langendorff isolated heart system and organ bath system. Hypertension was induced in male albino Wistar rats by oral administration of $N^{\omega}$-nitro-L-arginine methyl ester hydrochloride (L-NAME) ( $40 \mathrm{mg} / \mathrm{kg}$ body weight (b.w.)) in drinking water for 4 weeks. VA was orally administered at a dose of $40 \mathrm{mg} / \mathrm{kg}$ b.w. L-NAME-treated rats showed impaired cardiac ventricular and vascular function, evaluated by Langendorff isolated heart system and organ bath studies, respectively; a significant increase in the lipid peroxidation products such as thiobarbituric acid-reactive substances and lipid hydroperoxides in aorta; and a significant decrease in the activities of superoxide dismutase, catalase, glutathione peroxidase and levels of GSH, vitamin C and vitamin $\mathrm{E}$ in aorta. Fibrotic remodelling of the aorta and heart were assessed by Masson's Trichrome staining and Van Gieson's staining, respectively. In addition, L-NAME rats showed increased heart fibronectin expression assessed by immunohistochemical analysis. VA supplementation throughout the experimental period significantly normalised cardiovascular function, oxidative stress, antioxidant status and fibrotic remodelling of tissues. These results of the present study conclude that VA acts as a protective agent against hypertensionassociated cardiovascular remodelling.

Key words: Hypertension: Cardiovascular remodelling: Oxidative stress: Fibrosis: Veratric acid

CVD is the leading cause of death worldwide, and its major risk factor is hypertension ${ }^{(1,2)}$. Hypertension affects approximately $25 \%$ of the adult population worldwide, and its prevalence is predicted to increase by $60 \%$ by $2025^{(3)}$. The important role in the pathophysiology of hypertensive disease was played by myocardial remodelling ${ }^{(4)}$. In addition, cardiac hypertrophy and fibrosis that develop as an adaptive response to pressure overload ends with progressive heart disease ${ }^{(5,6)}$.

Oxidative stress had an important role in the pathogenesis and development of $\mathrm{CVD}^{(7)}$. Recent studies have shown that systemic arterial hypertension was induced by chronic administration of L-arginine analogue such as $N^{\omega}$-nitro-L-arginine methyl ester hydrochloride (L-NAME) to rats by blocking the endothelial nitric oxide synthase (NOS) isoform and in turn reducing the NO biosynthesis. This leads to endothelial dysfunction followed by impaired vasodilation and inflammatory phenotypic changes in the coronary vascular wall ${ }^{(8,9)}$. Earlier reports highlight the crucial role of vascular endothelial cells in the pathogenesis of the arterial wall alterations and hypertension $^{(10)}$. Inhibition of oxidative stress maintains bioavailability of $\mathrm{NO}$, and therefore the agents with antioxidant properties can improve regulation of vascular tone by inactivating free radicals and increasing NO bioavailability ${ }^{(11)}$.

In recent years, increased consumption of dietary agents such as fruits, vegetables, whole grains and fish has a crucial role in the control of CVD including hypertension ${ }^{(12)}$. The protective effects of plant intake can be because of the presence of phenolic compounds and flavonoids. Phenolic acids are hydroxylated

Abbreviations: ACh, acetylcholine; b.w., body weight; CAT, catalase; FN, fibronectin; GPx, glutathione peroxidase; L-NAME, $N^{\omega}$-nitro-L-arginine methyl ester hydrochloride; LOOH, lipid hydroperoxides; SOD, superoxide dismutase; TBARS, thiobarbituric acid-reactive substances; VA, veratric acid.

* Corresponding author: Dr B. Raja, email drrajaau@gmail.com 


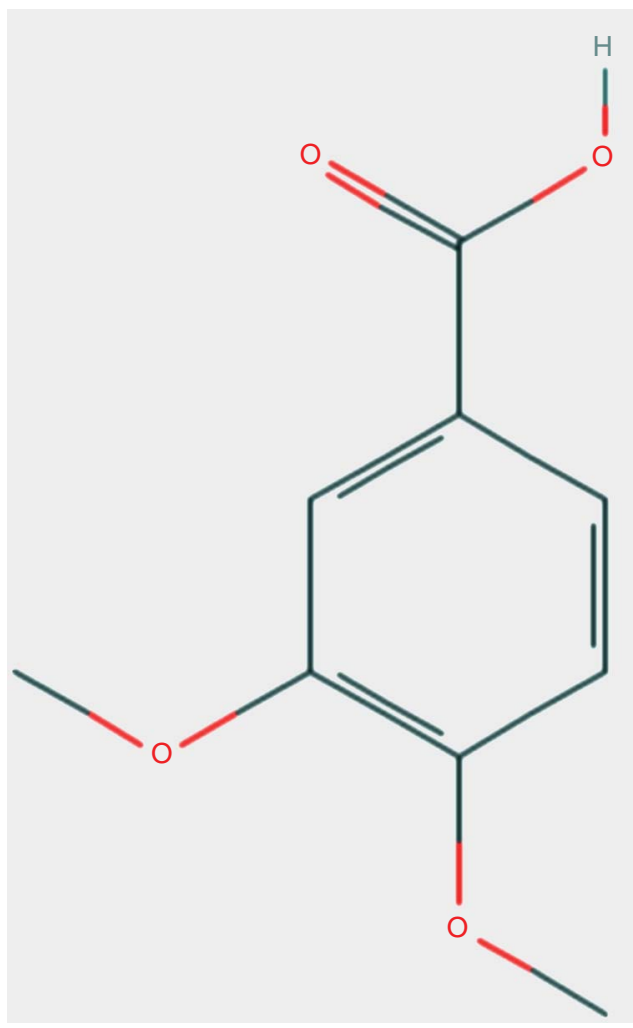

Fig. 1. Structure of veratric acid; the chemical structure was obtained from the PubChem database (pubchem.ncbi.nlm.nih.gov).

derivatives of benzoic and cinnamic acids ${ }^{(13)}$, and veratric acid (VA) (Fig. 1), one of the major benzoic acid derivatives from vegetables and fruits that occurs naturally in Tabebuia impetiginosa, is reported to have antibacterial, antifungal, antiinflammatory, antispasmodic ${ }^{(14)}$ and antioxidant activities ${ }^{(15)}$. Phenolic acids have a beneficial role in the prevention of many human diseases, particularly atherosclerosis and cancer, because of their antioxidant properties ${ }^{(16)}$. In our previous phase of experiments, we reported the antihypertensive, free-radical-scavenging and anti-hyperlipidaemic effects of VA in L-NAME-induced hypertensive rats ${ }^{(17,18)}$. In this study, we evaluated the effects of VA on ventricular function, endothelium-dependent acetylcholine (ACh)-induced relaxation in aorta, oxidative stress, heart and aortic structural remodelling in a rat model of arterial hypertension induced by L-NAME.

\section{Methods}

\section{Animals and chemicals}

Healthy male albino Wistar rats (180-220 g) were obtained from the Central Animal House, Department of Experimental Medicine, Rajah Muthiah Medical College and Hospital, Annamalai University, India. They were housed (three rats per cage $)$ in polypropylene cages $(47 \times 34 \times 20 \mathrm{~cm})$ lined with husk, renewed every $24 \mathrm{~h}$ and maintained in an air-conditioned room $\left(25(\mathrm{sD} 3)^{\circ} \mathrm{C}\right)$ with a $12 \mathrm{~h}$ light $-12 \mathrm{~h}$ dark cycle. Animals received the standard pellet diet (Kamadhenu Agencies) and water ad libitum. The whole experiment was carried out according to the guidelines of the Committee for the Purpose of Control and Supervision of Experiments on Animals, New Delhi, India and approved by the Institutional Animal Ethics Committee of Rajah Muthiah Medical College and Hospital (Reg No. 160/1999/ CPCSEA, approval number: 747), Annamalai University, Annamalainagar.

L-NAME and VA were purchased from Sigma-Aldrich. All other chemicals used in this study were of analytical grade obtained from Merck and HiMedia.

\section{Animal model of $\mathrm{N}^{\omega}$-nitro-L-arginine methyl ester hydrochloride-induced hypertension and veratric acid treatment}

Animals were given L-NAME in drinking water at a dosage of $40 \mathrm{mg} / \mathrm{kg}$ body weight (b.w.) for 4 weeks. VA was dissolved in $5 \%$ dimethyl sulfoxide (vehicle) and administered to rats orally everyday using an intragastric tube for a period of 4 weeks.

\section{Experimental protocol}

On the basis of our previous study, the dosage of VA was fixed as $40 \mathrm{mg} / \mathrm{kg}$ for this study ${ }^{(17)}$. Each of the following groups consisted of six animals - Group I: control; Group II: rats were treated with VA ( $40 \mathrm{mg} / \mathrm{kg}$ b.w.); Group III: rats were given LNAME ( $40 \mathrm{mg} / \mathrm{kg}$ b.w.); Group IV: rats were co-administered with L-NAME ( $40 \mathrm{mg} / \mathrm{kg}$ b.w.) and VA ( $40 \mathrm{mg} / \mathrm{kg}$ b.w.). Vehicle alone was administered to control (Group I) and L-NAME control rats (Group III) orally using an intragastric tube daily for 4 weeks.

\section{Preparation of tissue homogenates}

After the completion of the experimental period, the rats were anaesthetised and killed by cervical dislocation. Aortic tissues were sliced into pieces and homogenised in $0 \cdot 1 \mathrm{M}-$ Tris- $\mathrm{HCl}$ buffer in cold condition ( $\mathrm{pH} 7.4$ ) to give $20 \%$ homogenate $(\mathrm{w} / \mathrm{v})$. The homogenate was centrifuged at $560 \boldsymbol{g}$ for $10 \mathrm{~min}$ at $4^{\circ} \mathrm{C}$. The supernatant was separated and used for various biochemical estimations.

\section{Lipid peroxidation products and antioxidants}

The levels of thiobarbituric acid-reactive substances (TBARS) and lipid hydroperoxides (LOOH) in aorta were estimated by the methods of Niehaus \& Samuelsson ${ }^{(19)}$ and Jiang et al. $^{(20)}$, respectively. The activities of enzymatic antioxidants such as superoxide dismutase (SOD), catalase (CAT) and glutathione peroxidase (GPx) in aorta were estimated by the methods of Kakkar et $a l^{(21)}$, Sinha ${ }^{(22)}$ and Rotruck et $a l^{(23)}$, respectively. The levels of non-enzymatic antioxidants such as GSH, vitamin $\mathrm{C}$ and vitamin $\mathrm{E}$ in aorta were estimated by the methods of Ellman $^{(24)}$, Roe \& Kuether ${ }^{(25)}$ and Baker et $a l^{(26)}$, respectively.

\section{Langendorff isolated heart study}

The left ventricular function of the rat heart was assessed using the Langendorff isolated heart preparation. Briefly, after 
anaesthesia, the heart was excised and placed in cooled $\left(4^{\circ} \mathrm{C}\right)$ Krebs-Henseleit bicarbonate solution (composition (mM): 118 $\mathrm{NaCl}, 4 \cdot 7 \mathrm{KCl}, 1 \cdot 2 \mathrm{MgSO}_{4}, 1 \cdot 2 \mathrm{KH}_{2} \mathrm{PO}_{4}, 2 \cdot 3 \mathrm{CaCl}_{2}, 25 \cdot 0 \mathrm{NaHCO}_{3}$ and 11.0 glucose). The heart was then attached to the cannula through the aorta and retrogradely perfused with the Krebs solution maintained at $37^{\circ} \mathrm{C}$ and continuously gassed with a mixture of $95 \% \mathrm{O}_{2}-5 \% \mathrm{CO}_{2}$. Perfusion pressure was kept constant at $80 \mathrm{mmHg}$. An elastic water-filled balloon was introduced into the left ventricle through a left atrial incision. Isovolumetric recordings of the rate of pressure development $(+d p / d t)$ and rate of pressure decline $(-d p / d t)$ were obtained from the ventricular balloon connected via fluid-filled tubing to a Pressure Transducer (ADInstruments) linked with a PowerLab data acquisition unit (ADInstruments) ${ }^{(27)}$.

\section{Tension recording: organ bath study}

After anaesthesia, the thoracic aortas were carefully removed and transferred to cold modified Krebs-Henseleit solution (MKHS) of the following composition (mM): $118 \mathrm{NaCl}, 4.7 \mathrm{KCl}$, $1.2 \mathrm{MgSO}_{4}, 1 \cdot 2 \mathrm{KH}_{2} \mathrm{PO}_{4}, 11 \cdot 1$ D-glucose, 11.9 $\mathrm{NaHCO}_{3}$ and 2.5 $\mathrm{CaCl}_{2}, \mathrm{pH} 7 \cdot 4$. Aortas were cleared of connective tissue and cut into rings of about $2-3 \mathrm{~mm}$ length. The aortic ring segments were mounted on two stainless steel hooks and suspended in $10 \mathrm{ml}$ organ baths containing MKHS, maintained at $37^{\circ} \mathrm{C}$ and aerated continuously with $95 \% \mathrm{O}_{2}-5 \% \mathrm{CO}_{2}$ mixture. A passive tension of $1.5 \mathrm{~g}$ was applied during the equilibration period of $90 \mathrm{~min}$, during which the bath solution was changed every $15 \mathrm{~min}$. Tension was continuously recorded using a highsensitivity force transducer and recorded in a computer using a Chart version 5.4.1 software programme (PowerLab).

After the equilibration period, tissue viability was examined by recording the contraction to high $\mathrm{K}^{+}(80 \mathrm{~mm})$-depolarising solution, in which part of the $\mathrm{NaCl}$ in the MKHS was replaced with an equimolar concentration of $\mathrm{KCl}$. Cumulative concentrationresponse curves to relaxants were elicited in arterial segments pre-contracted with 1-3 $\mu \mathrm{m}$-phenylephrine. Endothelial integrity was examined by adding $3 \mu \mathrm{m}$-ACh at the plateau phase of phenylephrine contraction. In endothelium-intact rings, ACh $(3 \mu \mathrm{M})$ caused $80 \%$ relaxation. To examine the influence of membrane depolarisation on the vasodilator responses to $\mathrm{ACh}$, arterial rings were pre-contracted with $\mathrm{K}^{+}(40 \mathrm{~mm})$-depolarising solution. Separate arterial rings were used for control and treatment groups for the assessment of vasodilator responses to $\mathrm{ACh}$.

\section{Histopathology of heart and aorta}

The heart and aorta samples obtained from all experimental groups were cleared of blood and immediately fixed in $10 \%$ buffered neutral formalin. Heart and aorta sections $(5 \mu \mathrm{m})$ were prepared from processed paraffin-embedded samples. Aortic sections were stained with Masson's Trichrome. Heart sections were stained with Van Gieson's staining. Tissue sections were examined under a light microscope and photomicrographs were taken.

\section{Immunohistochemistry}

Paraffin-embedded tissue sections were dewaxed and rehydrated through grade ethanol to distilled water. Endogenous peroxidase was blocked by incubation with $3 \% \mathrm{H}_{2} \mathrm{O}_{2}$ in methanol for $10 \mathrm{~min}$. The antigen retrieval was achieved by microwave in citrate buffer solution $\left(2 \cdot 1 \mathrm{~g}\right.$ citric acid/l D. $\mathrm{H}_{2} \mathrm{O}$; $0.37 \mathrm{~g}$ EDTA $/ 1$ D. $\mathrm{H}_{2} \mathrm{O} ; 0.2 \mathrm{~g}$ trypsin) $(\mathrm{pH} 6.0)$ for $10 \mathrm{~min}$, followed by washing step with Tris-buffered saline $(8 \mathrm{~g} \mathrm{NaCl}$; $0 \cdot 605 \mathrm{~g}$ Tris) ( $\mathrm{pH} \mathrm{7.6).} \mathrm{The} \mathrm{tissue} \mathrm{sections} \mathrm{were} \mathrm{then} \mathrm{incubated}$ with blocking reagent for $15 \mathrm{~min}$ at room temperature to block non-specific binding sites. The tissue sections were then incubated with the polyclonal anti-fibronectin antibody with 1:500 dilution overnight at $4^{\circ} \mathrm{C}$. The bound primary antibody was detected by incubation with the secondary antibody conjugated with horseradish peroxidase for $30 \mathrm{~min}$ at room temperature. After rinsing with Tris-buffered saline, the antigen-antibody complex was detected using 3,3'-diaminobenzidine, the substrate of horseradish peroxidase. Each slide was microscopically analysed, and the percentage of the positively stained area was enumerated semi-quantitatively. The percentage of positive area was scored as follows: $3+=$ strong staining, $>50 \%$ of area was stained; $2+=$ moderate staining, between 20 and $50 \%$ of area was stained; $1+=$ weak staining, between 1 and $20 \%$ of area was stained; $0=$ negative, $<1 \%$ of area was stained ${ }^{(28)}$.

\section{Statistical analysis}

Data were analysed by one-way ANOVA followed by Duncan's multiple-range test using SPSS version 20.0. For aortic relaxation, data were analysed by two-way ANOVA followed by Bonferroni's post hoc test. Values are represented as mean values and standard deviations of six animals in each group. Values were considered significant when $P<0 \cdot 05$.

\section{Results}

\section{Effect of veratric acid on lipid peroxidation and antioxidants}

Table 1 shows the effect of VA on the levels of TBARS and $\mathrm{LOOH}$ in the aortic tissues of L-NAME-induced hypertensive rats. The L-NAME rats exhibited a significant increase in the levels of TBARS and LOOH. The administration of VA reduced the levels of TBARS and LOOH significantly $(P<0.05)$.

Table 1 illustrates the effect of VA on the activities of SOD, CAT and GPx in the aortic tissues of L-NAME hypertensive rats. The activities of SOD, CAT and GPx decreased significantly $(P<0.05)$ in L-NAME rats, and the administration of VA significantly increased these enzymatic antioxidants.

Table 1 portrays the effect of VA on the levels of vitamin C, vitamin $\mathrm{E}$ and GSH in the aortic tissues of control and L-NAMEinduced hypertensive rats. The levels of GSH, vitamin $\mathrm{C}$ and vitamin $\mathrm{E}$ decreased significantly in L-NAME rats, and administration of VA significantly $(P<0.05)$ increased the levels of these non-enzymatic antioxidants.

\section{Effect of veratric acid on cardiac function: Langendorff study}

The systolic contractility of the isolated heart was measured by the first temporal derivative of the left ventricular pressure (LVP) positive development $(+d p / d t, \mathrm{mmHg} / \mathrm{s})$, and the isovolumetric 
Table 1. Effect of veratric acid (VA) on lipid peroxidation and antioxidants in the aorta of experimental hypertensive rats (Mean values and standard deviations; six animals)

\begin{tabular}{|c|c|c|c|c|c|c|c|c|}
\hline \multirow[b]{2}{*}{ Parameters } & \multicolumn{2}{|c|}{ Control } & \multicolumn{2}{|c|}{ Control + VA (40 mg/kg) } & \multicolumn{2}{|c|}{ L-NAME (40 mg/kg) } & \multicolumn{2}{|c|}{ L-NAME + VA $(40 \mathrm{mg} / \mathrm{kg})$} \\
\hline & Mean & SD & Mean & SD & Mean & SD & Mean & SD \\
\hline TBARS (mм/100 g wet tissue) & 0.40 & 0.04 & 0.38 & 0.03 & $1.90^{*}$ & $0 \cdot 10$ & $0.73 \dagger$ & 0.52 \\
\hline $\mathrm{LOOH}(\mathrm{mm} / 100 \mathrm{~g}$ wet tissue) & $73 \cdot 25$ & 5.25 & $71 \cdot 12$ & 4.32 & $115 \cdot 51^{*}$ & 8.03 & $84.23 \dagger$ & 8.12 \\
\hline Superoxide dismutase ( $\mathrm{U}^{\mathrm{a}} / \mathrm{mg}$ protein) & 13.46 & 1.25 & $12 \cdot 36$ & 2.84 & $5.98^{*}$ & 0.45 & $8.96 \dagger$ & 0.47 \\
\hline Catalase ( $\mathrm{U}^{\mathrm{b}} / \mathrm{mg}$ protein) & $56 \cdot 82$ & 5.32 & 54.42 & $5 \cdot 12$ & $30 \cdot 32^{*}$ & 2.43 & $50.34 t$ & 3.83 \\
\hline Glutathione peroxidase (Uc/mg protein) & 9.34 & 2.59 & 10.83 & 1.9 & $3.05^{\star}$ & 1.72 & $7.72 \dagger$ & 3.02 \\
\hline Vitamin C ( $\mu \mathrm{g} / \mathrm{mg}$ protein) & 0.60 & 0.12 & 0.61 & 0.08 & $0.25^{\star}$ & 0.07 & $0.57 \dagger$ & 0.081 \\
\hline Vitamin $E(\mu \mathrm{g} / \mathrm{mg}$ protein) & 4.59 & 0.39 & 4.60 & 0.34 & $1 \cdot 31^{*}$ & 0.36 & $3.76 \dagger$ & 0.53 \\
\hline GSH ( $\mu \mathrm{g} / \mathrm{mg}$ protein) & 8.87 & 1.46 & 8.88 & 1.40 & $3 \cdot 67^{\star}$ & 1.38 & $7.76 \dagger$ & 0.95 \\
\hline
\end{tabular}

L-NAME, $N^{\omega}$-nitro-L-arginine methyl ester hydrochloride; TBARS, thiobarbituric acid-reactive substances; LOOH, lipid hydroperoxides; $\mathrm{U}^{\mathrm{a}}$, enzyme concentration required to inhibit the chromogen produced by $50 \%$ in 1 min under standard condition; $U^{b}$, micromoles of $\mathrm{H}_{2} \mathrm{O}_{2}$ consumed per minute; $U^{\mathrm{c}}$, micrograms of GSH utilised per minute.

* Mean values were significantly different compared with control $(P<0.05$; Duncan's multiple-range test).

$\dagger$ Mean values were significantly different compared with L-NAME $(P<0.05$; Duncan's multiple-range test).

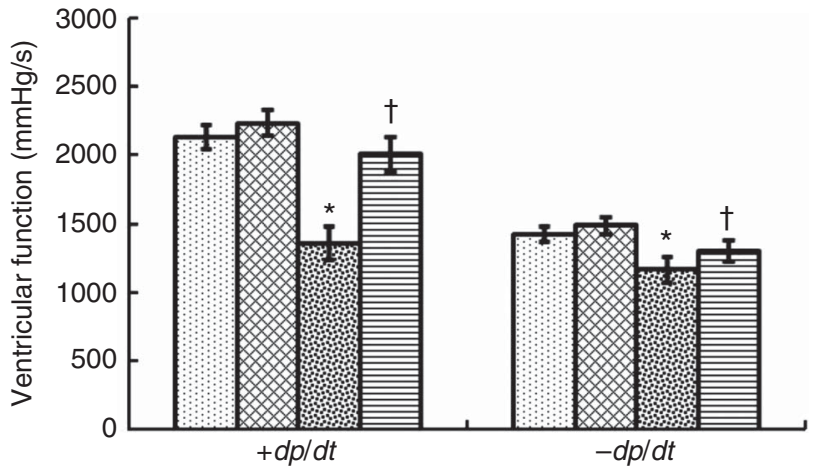

Fig. 2. Veratric acid improved cardiac ventricular function in experimental hypertensive rats. Values are means (six animals), and standard deviations represented by vertical bars. * Mean values were significantly different compared with control $(P<0.05$; Duncan's multiple-range test). $\dagger$ Mean values were significantly different compared with $N^{\omega}$-nitro-L-arginine methyl ester hydrochloride (L-NAME) $(P<0.05$; Duncan's multiple-range test). $\because$, Control; \% control + veratric acid; 8 , L-NAME; 茞, L-NAME + veratric acid.

relaxation was measured by the first temporal derivative of the LVP negative development $(-d p / d t, \mathrm{mmHg} / \mathrm{s})$. In the heart of L-NAME rats, the rate of LVP rise $(+d p / d t, \mathrm{mmHg} / \mathrm{s})$ and the rate of LVP decline $(-d p / d t, \mathrm{mmHg} / \mathrm{s})$ were significantly $(P<0 \cdot 05)$ reduced. VA treatment significantly $(P<0.05)$ promoted ventricular function in L-NAME rats (Fig. 2).

\section{Effect of veratric acid on vascular function: organ bath study}

Fig. 3 and Table 2 show concentration-dependent relaxation to ACh in phenylephrine pre-contracted endothelium-intact rings from aorta of experimental rats. Sensitivity of the aortic rings to ACh from rats given L-NAME was significantly $(P<0.05)$ reduced. When aortic tissues from L-NAME rats given VA were challenged with ACh, the vasodilation was almost restored.

\section{Masson's Trichrome-stained histopathology of aorta}

Fig. 4(a)-(d) illustrates photomicrographs of Masson's Trichrome staining of the thoracic aorta of control and L-NAME-administered

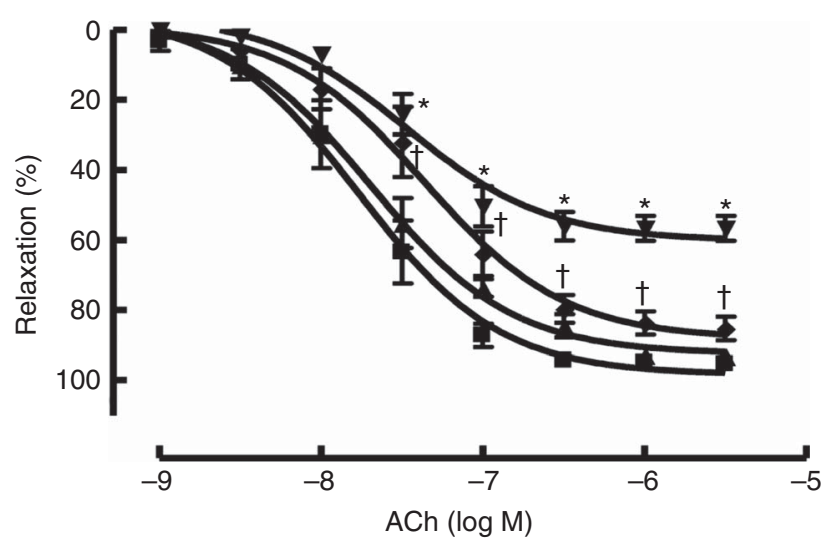

Fig. 3. Veratric acid recovered vascular function in experimental hypertensive rats. Values are means (six animals), and standard deviations. * Mean values were significantly different compared with control $(P<0.05$; Bonferroni's post hoc test). † Mean values were significantly different compared with $N^{\omega}$-nitro-Larginine methyl ester hydrochloride (L-NAME) $(P<0.05$; Bonferroni's post hoc test). ACh, acetylcholine; $\mathbf{\square}$, control; $\mathbf{\Delta}$, control + veratric acid; $\boldsymbol{\nabla}, \mathrm{I}-\mathrm{NAME}$; $\checkmark, \mathrm{L}-\mathrm{NAME}+$ veratric acid.

rats. Aorta from control rats showed normal architecture (Fig. 4(a)). Control group treated with VA also showed normal thoracic aorta (Fig. 4(b)). Fig. 4(c) showed that L-NAME-treated rats exhibited increased endothelial cells and interstitial collagen accumulation (stained blue). VA administered to L-NAME rats revealed reduced collagen accumulation (stained blue) as compared with the L-NAME rats (Fig. 4(d)).

\section{Van Gieson's stained histopathology of the heart}

Fig. 5(a)-(d) demonstrates the Van Gieson's staining of the heart. L-NAME hypertensive rats exhibited increase in the interstitial collagen accumulation and fibrosis stained red (Fig. 5(c)). VA supplementation $(40 \mathrm{mg} / \mathrm{kg})$ in L-NAME rats showed reduction in the collagen accumulation (Fig. 5(d)). Control and control treated with VA showed normal cardiac architecture without any pathological changes (Fig. 5(a) and (b)) 
Effect of veratric acid on fibronectin expression: immunohistochemical analysis

In L-NAME-induced hypertensive rats, the expression of heart fibronectin (FN) was higher when compared with control rats (Fig. 6). Treatment with VA ( $40 \mathrm{mg} / \mathrm{kg}$ ) decreased the expression of heart FN in L-NAME-induced hypertensive rats.

Table 2. Effect of veratric acid (VA) on acetylcholine-induced relaxations in endothelium-intact aorta of experimental hypertensive rats (Mean values and standard deviations; six animals)

\begin{tabular}{llllll}
\hline & \multicolumn{2}{c}{$p D_{2}$} & & \multicolumn{2}{c}{$E_{\max }(\%)$} \\
\cline { 2 - 3 } Groups & Mean & SD & & Mean & SD \\
\hline Control & 7.76 & 0.09 & & 98.40 & 3.02 \\
Control + VA (40 mg/kg) & 7.69 & 0.09 & & 94.54 & 2.80 \\
L-NAME & $7.27^{\star}$ & 0.11 & & $60.29^{\star}$ & 2.54 \\
L-NAME + VA (40 mg/kg) & $7.52 \dagger$ & 0.10 & & $88.25 \dagger$ & 3.50 \\
\hline
\end{tabular}

L-NAME, $N^{\omega}$-nitro-L-arginine methyl ester hydrochloride.

${ }^{*}$ Mean values were significantly different compared with control $(P<0.05$; Bonferroni's post hoc test).

† Mean values were significantly different compared with L-NAME $(P<0.05$; Bonferroni's post hoc test).
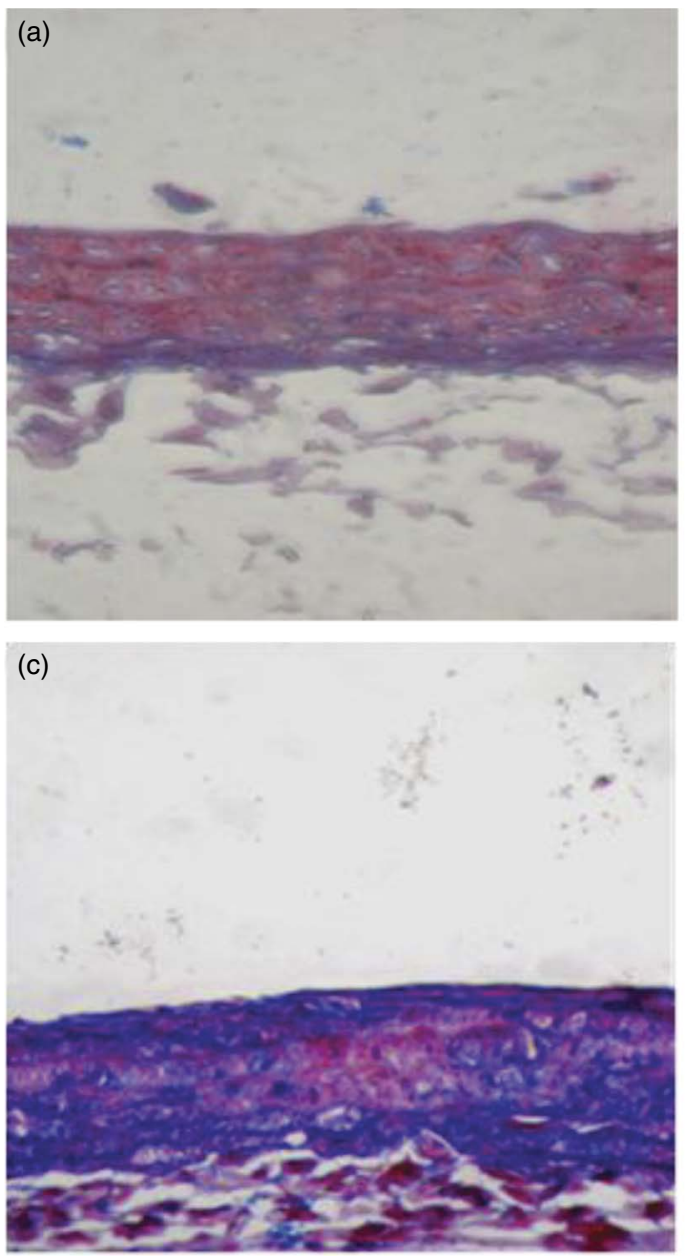

\section{Discussion}

NO participates in the modulation of vascular tone, and it is synthesised and released by endothelial cells ${ }^{(29)}$. In addition, NO is important in cellular events such as vascular smooth muscle cell proliferation ${ }^{(8)}$. It is well established that arterial hypertension was caused by the chronic inhibition of NO biosynthesis by administration of L-NAME, an L-arginine analogue $\mathrm{e}^{(30)}$, characterised by cardiac remodelling ${ }^{(31)}$, dysfunction of endothelial-dependent relaxation ${ }^{(32)}$ and renal function changes ${ }^{(33)}$. L-NAME-induced hypertension is a wellestablished model of experimental hypertension ${ }^{(34)}$.

Oxidative stress has an important role in the development of hypertension, originated through excessive production of reactive oxygen species (ROS) ${ }^{(35)}$. Hypertension results in the production of large amounts of ROS such as superoxide, hydrogen peroxide and hydroxyl radicals ${ }^{(13)}$. Our results showed that the lipid peroxidation products, measured as TBARS and $\mathrm{LOOH}$, were increased in the aortic tissues of L-NAME-induced hypertensive rats. Lipid peroxidation is an important pathogenic event in hypertension, and its complications were associated with the accumulation of $\mathrm{LOOH}^{(13)}$.
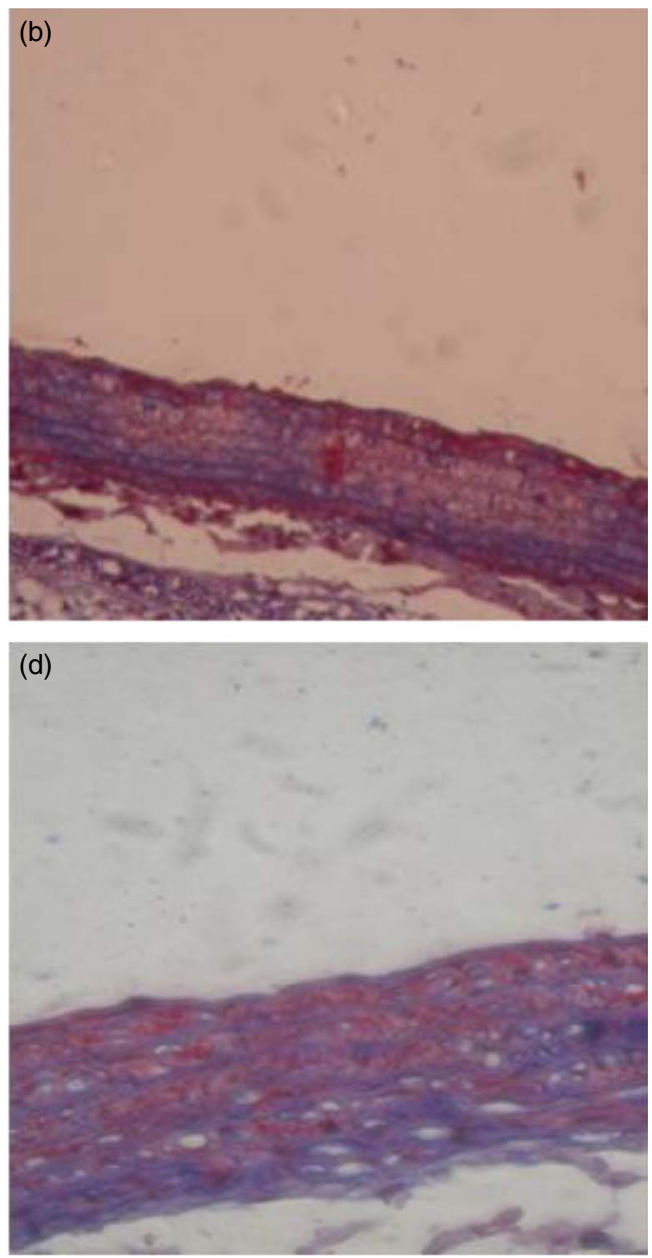

Fig. 4. Photomicrographs of Masson's Trichrome-stained sections of thoracic aorta from control and $N^{\omega}$-nitro-L-arginine methyl ester hydrochloride (L-NAME)-induced hypertensive rats $(40 \times)$. (a) Control rats showing normal pathological staining. (b) Control + veratric acid (VA) (40 mg/kg)-treated rats showing negative staining without any pathological alterations. (c) L-NAME-induced hypertensive rats showing increased endothelial cells and interstitial collagen accumulation (stained blue). (d) L-NAME + VA ( $40 \mathrm{mg} / \mathrm{kg}$ ) revealed reduced collagen accumulation (stained blue) as compared with the hypertensive rats. 

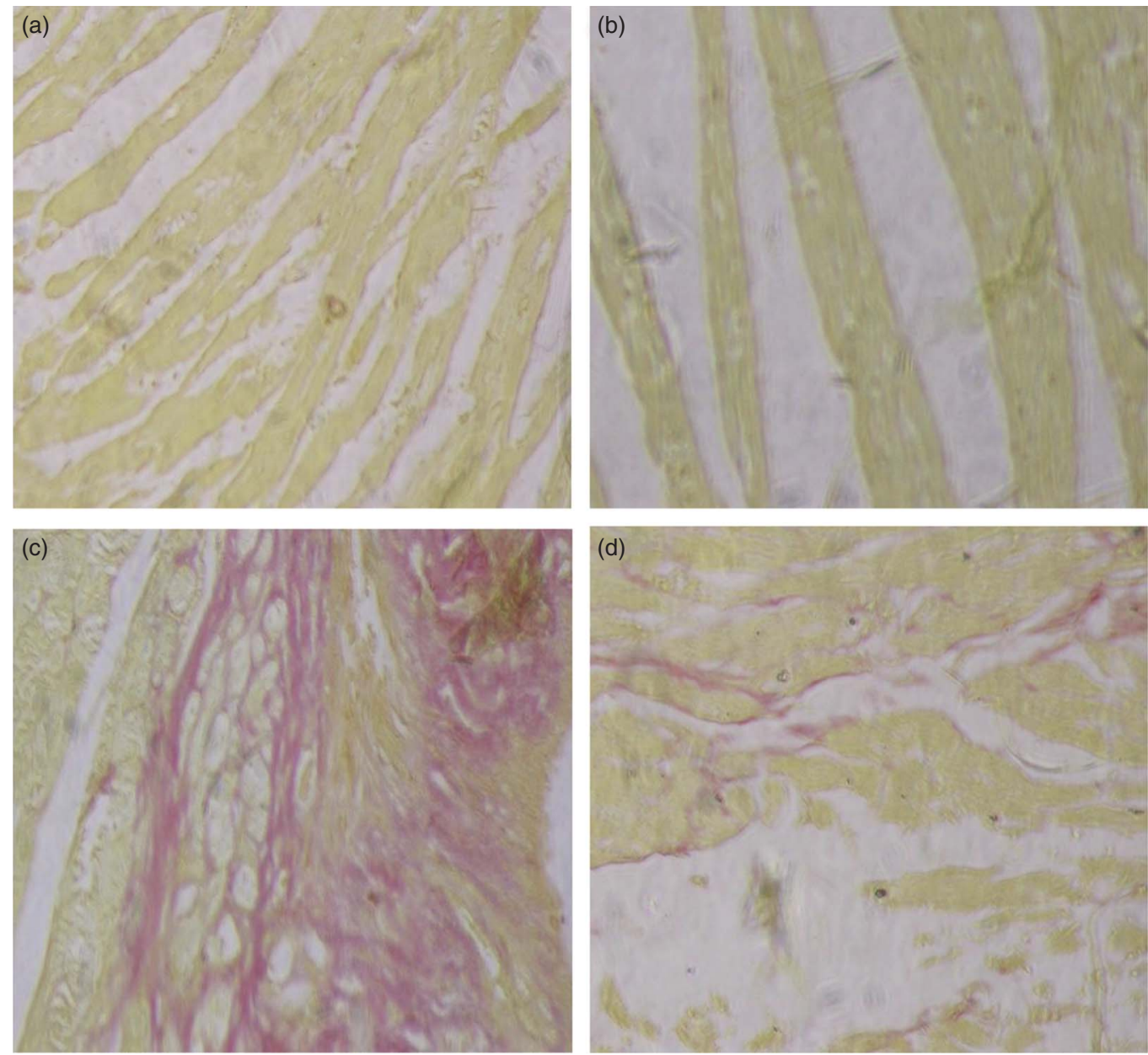

Fig. 5. Photomicrographs of Van Gieson's stained sections of heart from control and $N^{\omega}$-nitro-L-arginine methyl ester hydrochloride (L-NAME)-induced hypertensive rats (40x). (a) Control rats showing normal pathological staining. (b) Control + veratric acid (VA) $(40 \mathrm{mg} / \mathrm{kg})$-treated rat showing negative staining without any pathological alterations. (c) L-NAME-induced hypertensive rats showing pathological alteration with positive staining (fibrosis and collagen deposition). (d) L-NAME + VA $(40 \mathrm{mg} / \mathrm{kg})$ rats showing reduced positive staining.

L-NAME rats show increased levels of lipid peroxides, which might be because of free-radical-mediated membrane damage. Oral administration with VA $(40 \mathrm{mg} / \mathrm{kg})$ significantly decreased the levels of TBARS and LOOH in L-NAME-treated rats. This reveals the anti-lipidperoxidative role of VA that is probably mediated by its ability to scavenge free radicals ${ }^{(17)}$.

The first line of cellular defence against oxidative injury was offered by free-radical-scavenging enzymes such as SOD, CAT and GPx, decomposing superoxide and hydrogen peroxide, otherwise interacting to form the more reactive hydroxyl radical $^{(36)}$. The important process responsible for the effective removal of oxidative stress in intracellular organelles is the equilibrium between the enzymatic antioxidants and free radicals ${ }^{(37)}$. Our previous study suggested that the activities of antioxidant enzymes SOD, CAT and GPx were significantly decreased in the erythrocytes and tissues of L-NAME-induced hypertensive rats and increased after treatment with $\mathrm{VA}^{(17)}$. The result of the present study is parallel with our previous report showing that VA administration significantly improved the activities of SOD, CAT and GPx in the aortic tissue.
The increased activities of these enzymes in VA-treated rats might be because of its free-radical-scavenging ability ${ }^{(17)}$.

The residual free radicals escaping from decomposition enzymes were scavenged by the non-enzymatic antioxidants, namely vitamin $\mathrm{C}$, vitamin $\mathrm{E}$ and $\mathrm{GSH}^{(38)}$. Vitamin $\mathrm{C}$ present in the aqueous environment reduces free radicals present on the surface of the membrane owing to its multiple antioxidant properties ${ }^{(39)}$. The most effective lipid-soluble antioxidant in the biological system is vitamin E. GSH is directly involved in the removal of superoxide radicals, peroxyl radicals and singlet oxygen ${ }^{(40)}$.

In the current study, the levels of non-enzymatic antioxidants were declined in L-NAME rats. Increased use of these nonenzymatic antioxidants for the neutralisation of free radicals might be the reason for its decreased levels ${ }^{(41)}$. Our previous report explored the protective effect of VA on non-enzymatic antioxidant system ${ }^{(17)}$. Consistent with the previous report, in this study VA treatment enhanced the levels of non-enzymatic antioxidants, which suggests that this compound might be potentially useful in counteracting free-radical-mediated oxidative stress caused by lipid peroxidation ${ }^{(17)}$. 

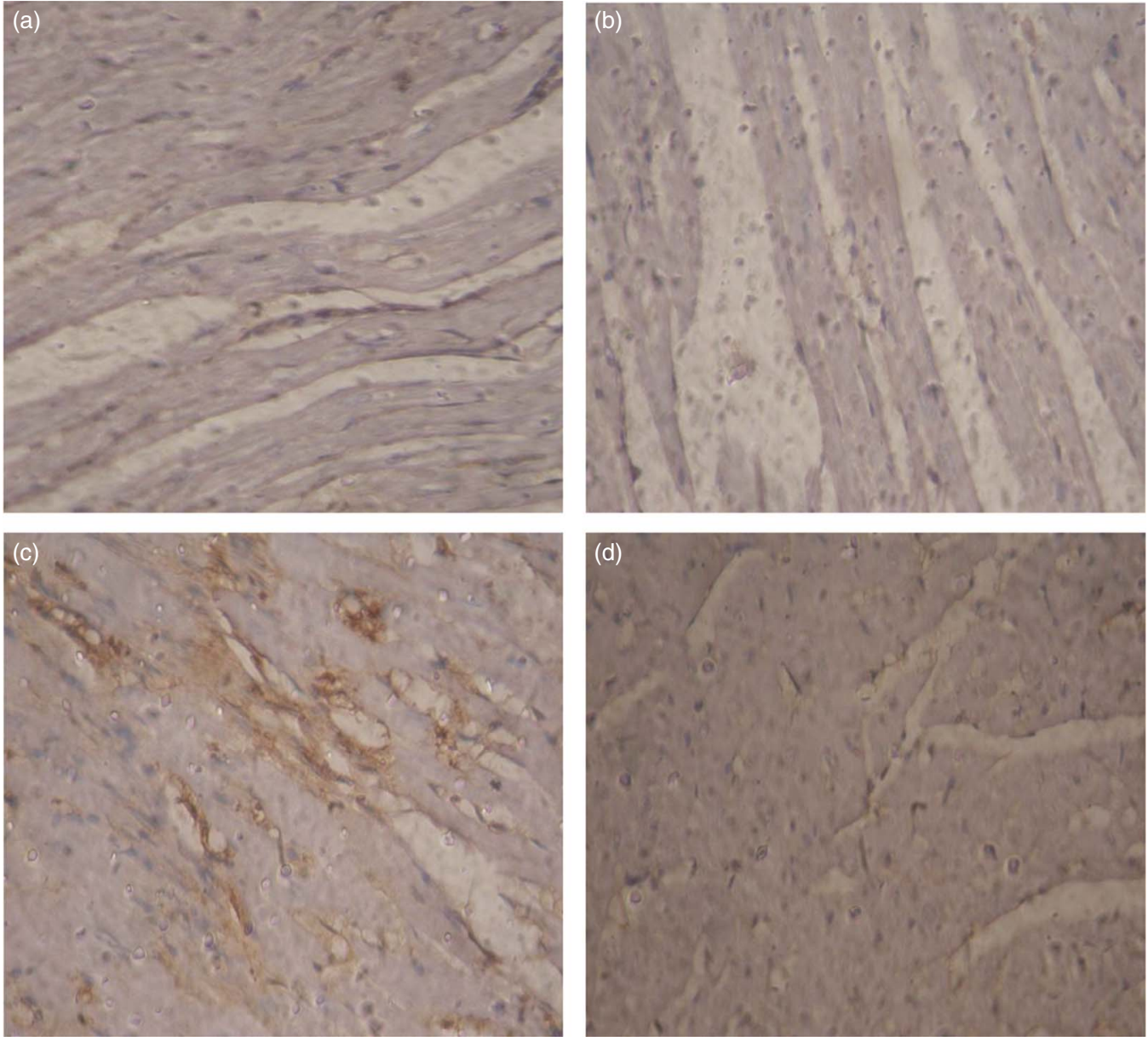

Fig. 6. Representative photomicrographs of immunohistochemistry for fibronectin in heart of control and $N^{\omega}$-nitro-L-arginine methyl ester hydrochloride (L-NAME)-induced hypertensive rats (40x). (a) Control rats showing normal architecture without any pathological alterations $(0=$ negative, $<1 \%$ of area staining). (b) Control + veratric acid (VA) $(40 \mathrm{mg} / \mathrm{kg})$-treated rats showing near normal architecture $(0=$ negative, $<1 \%$ of area staining). (c) L-NAME hypertensive rats showing increased fibronectin-positive staining $(2+=$ moderate staining, between 20 and $50 \%$ of area was stained). (d) L-NAME $+V A(40 \mathrm{mg} / \mathrm{kg})$-treated rat showing diminished fibronectin expression ( $1+=$ weak staining, between 1 and $20 \%$ of area was stained).

Hiremath et $a l^{(42)}$ indicated that fibrosis was induced by oxidative stress generated during hypertensive condition. The exaggeration in the rate of synthesis and stabilisation of matrix and/or decrease in the capacity of degradation lead to the development of fibrosis ${ }^{(43)}$. The accumulation of collagen in the heart wall, an adaptive-compensatory mechanism to increased haemodynamic load, leads to a loss of wall compliance, and eventually to heart failure ${ }^{(44)}$. There are early reports of increased collagen synthesis in the arterial wall in hypertension that occurred globally in L-NAME hypertensive rats ${ }^{(45,46)}$. In this study, Masson's Trichrome staining of the thoracic aorta and Van Gieson's staining of the heart of L-NAME hypertensive rats showed collagen accumulation. VA supplementation throughout the experimental period considerably reduced the collagen deposition in L-NAME rats. These histological observations exhibited the protective role of VA in tissues of L-NAME hypertensive rats with its antioxidant property ${ }^{(17)}$.

Mulvany et $a l^{(47)}$ reported that arterial hypertension can reduce vessel and cardiac lumen size through hypertrophy, with wall thickening, and remodelling, with an increase in the thickness of the arterioles. Left ventricular hypertrophy and remodelling are frequently seen in hypertensive subjects ${ }^{(48)}$. Cardiac contractile function impairment is one of the major pathogenic features of cardiac remodelling. Hypertensioninduced ventricular dysfunction was assessed by the Langendorff isolated heart study. It was previously known that enhanced stiffness of the myocardium impedes ventricular contraction and relaxation caused by excess production and accumulation of extracellular matrix (ECM) structural proteins, or fibrosis, leading to distorted architecture and diastolic and systolic dysfunction of the heart ${ }^{(49,50)}$. From the antioxidant point of view, Mapanga et al. ${ }^{(51)}$ explored that oleanolic acid, an antioxidant agent, blunts hyperglycaemia-induced contractile dysfunction. Comparable with the previous report, in this study, L-NAME induction impairs the contractile function of the heart and VA treatment restores the ventricular function with its antioxidant property ${ }^{(17)}$.

Reduced production or activity of NO contributes to several human diseases, especially hypertension ${ }^{(52,53)}$. A previous report showed that L-NAME treatment causes deficiency in NO 


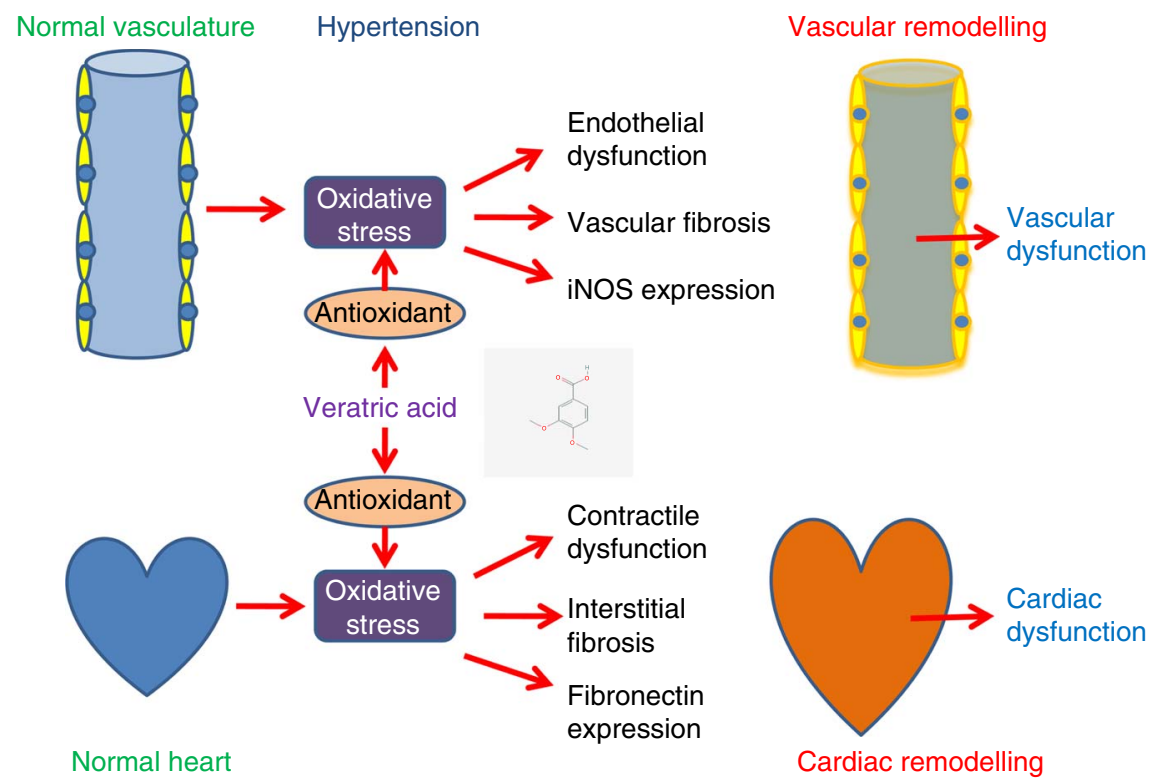

Fig. 7. Preventive role of veratric acid on cardiovascular remodelling. iNOS, inducible nitric oxide synthase.

production, which leads to the development of hypertension ${ }^{(8)}$. In the aorta of L-NAME-induced hypertensive rats, the endothelium-dependent relaxant response to ACh was markedly blunted ${ }^{(54)}$. Long-term inhibition of NOS results in decreased production of $\mathrm{NO}$, and an increased release of vasoconstrictors in endothelial cells eventually leads to endothelial dysfunction ${ }^{(55)}$. In the present work, the ACh-induced relaxation in endothelium-intact aorta was significantly augmented in the rats treated with VA when compared with that of the L-NAME-treated rats. It shows that VA, to an extent, preserves the functional capacity of the endothelium owing to its antioxidant capacity ${ }^{(17)}$.

In hypertensive heart disease, increased FN expression could contribute to ECM cell attachment and promote collagen deposition, as well as elevated gelatinase levels, leading to reactive myocardial fibrosis, which increases myocardial stiffness and reduces compliance ${ }^{(56)}$. It was already explored that, in deoxycorticosterone acetate plus salt rats with endothelindependent hypertension, the cardiac extracellular remodelling was associated with increased FN, matrix metalloproteinase activity and up-regulation of inflammatory mediators ${ }^{(57)}$. Moreover, in the models of pressure overload, the cardiac FN expression is elevated, and hypertrophy is caused by $\mathrm{FN}$ expression in the cultured cardiac myocytes ${ }^{(58)}$. In this study, immunohistochemical analysis explored that VA administration decreased the expression of $\mathrm{FN}$ in the heart of hypertensive rats, which might be because of the free-radical-scavenging ability of $\mathrm{VA}^{(17)}$, which could exert a beneficial action against pathophysiological alterations caused by free radicals.

Oxidative stress has been identified as one unifying mechanism in the pathogenesis of CVD. Antioxidants may need to be given as a pharmacotherapy, with the aim of reducing the burden of CVD. In conclusion, major findings from the present study demonstrated that VA supplementation could effectively prevent the cardiovascular dysfunction, lipid peroxidation, cardiac fibrosis, aortic fibrosis and FN expression. Further, VA has the potential to modulate alteration at the antioxidant level in L-NAME rats (Fig. 7). Our findings illustrate that in future VA may be used as a beneficial molecule in the treatment of hypertension-associated cardiovascular remodelling.

\section{Acknowledgements}

The authors thank Dr Madhavan R. Nirmal, Department of Oral Pathology, Rajah Muthiah Dental College and Hospital, Annamalai University, Tamil Nadu, India for carrying out the immunohistochemistry study.

This research received no specific grant from any funding agency, commercial or not-for-profit sectors.

The authors' contributions are as follows: B. R. and M. S. designed the research; M. S., J. M. and T. S. performed the experiments; P. P., S. K. and S. K. M. analysed the data; M. S., J. M. and T. S. wrote the paper; B. R. and S. K. M. revised the paper. All authors read and approved the final manuscript.

None of the authors has any conflicts of interest to declare.

\section{References}

1. Lopez AD, Mathers CD, Ezzati M, et al. (2006) Global and regional burden of disease and risk factors, 2001: systematic analysis of population health data. Lancet 367, 1747-1757.

2. Gu D, Reynolds K, Wu X, et al. (2002) Prevalence, awareness, treatment, and control of hypertension in China. Hypertension 40, 920-927.

3. Kearney PM, Whelton M, Reynolds K, et al. (2005) Global burden of hypertension: analysis of worldwide data. Lancet 365, 217-223.

4. Zhang Y, Shao L, Ma A, et al. (2014) Telmisartan delays myocardial fibrosis in rats with hypertensive left ventricular hypertrophy by TGF- $\beta 1 /$ Smad signal pathway. Hypertens Res 37, 43-49. 
5. Devereux RB \& Roman MJ (1999) Left ventricular hypertrophy in hypertension: stimuli, patterns, and consequences. Hypertens Res 22, 1-9.

6. Katz AM (1990) Cardiomyopathy of overload. A major determinant of prognosis in congestive heart failure. $N$ Engl J Med 322, 100-110.

7. Higashi Y, Noma K, Yoshizumi M, et al. (2009) Endothelial function and oxidative stress in cardiovascular diseases. Circ J 73, 411-418.

8. Sanada S, Node K, Minamino T, et al. (2003) Long-acting $\mathrm{Ca}^{2+}$ blockers prevent myocardial remodeling induced by chronic NO inhibition in rats. Hypertension 41, 963-967.

9. Rossi MA \& Colombini-Netto M (2001) Chronic inhibition of NO synthesis per se promotes structural intimal remodeling of the rat aorta. J Hypertens 19, 1567-1579.

10. Ferreira RN, Rocha VN, da Silva Torres T, et al. (2011) Beneficial effects of rosuvastatin on aortic adverse remodeling in nitric oxide-deficient rats. Exp Toxicol Pathol 63, $473-478$.

11. Kumar S, Saravanakumar M \& Raja B (2010) Efficacy of piperine, an alkaloidal constituent of pepper on nitric oxide, antioxidants and lipid peroxidation markers in L-NAME induced hypertensive rats. Int J Res Pharm Sci 1, 300-307.

12. Retelny VS, Neuendorf A \& Roth JL (2008) Nutrition protocols for the prevention of cardiovascular disease. Nutr Clin Pract 23, 468-476.

13. Kumar S, Prahalathan P \& Raja B (2011) Antihypertensive and antioxidant potential of vanillic acid, a phenolic compound in L-NAME-induced hypertensive rats: a dose-dependence study. Redox Rep 16, 208-215.

14. Narasimhan B, Ohlan S, Ohlan R, et al. (2009) Hansch analysis of veratric acid derivatives as antimicrobial agents. Eur J Med Chem 44, 689-700.

15. Szwajgier D, Pielecki J, Targonski Z, et al. (2005) Antioxidant activity of cinnamic and benzoic acid derivatives. Acta Sci Pol Technol Aliment 4, 129-149.

16. Mattila P \& Kumpulainen J (2002) Determination of free and total phenolic acids in plant-derived foods by HPLC with diode-array detection. J Agric Food Chem 50, 3660-3667.

17. Saravanakumar M \& Raja B (2011) Veratric acid, a phenolic acid attenuates blood pressure and oxidative stress in L-NAME induced hypertensive rats. Eur I Pharmacol 671, 87-94.

18. Saravanakumar M \& Raja B (2012) Effect of veratric acid on the cardiovascular risk of L-NAME-induced hypertensive rats. J Cardiovasc Pharmacol 59, 553-562.

19. Niehaus WG Jr \& Samuelsson B (1968) Formation of malonaldehyde from phospholipid arachidonate during microsomal lipid peroxidation. Eur J Biochem 6, 126-130.

20. Jiang ZY, Hunt JV \& Wolff SP (1992) Ferrous ion oxidation in the presence of xylenol orange for detection of lipid hydroperoxide in low density lipoprotein. Anal Biochem 202, 384-389.

21. Kakkar P, Das B \& Viswanathan PN (1984) A modified spectrophotometric assay of superoxide dismutase. Indian $J$ Biochem Biophys 21, 130-132.

22. Sinha AK (1972) Colorimetric assay of catalase. Anal Biochem 47, 389-394.

23. Rotruck JT, Pope AL, Ganther HE, et al. (1973) Selenium: biochemical role as a component of glutathione peroxidase. Science 179, 588-590.

24. Ellman GL (1959) Tissue sulfhydryl groups. Arch Biochem Biophys 82, 70-77.

25. Roe JH \& Kuether CA (1943) The determination of ascorbic acid in whole blood and urine through the 2,4-dinitrophenylhydrazine derivative of dehydroascorbic acid. J Biol Chem 147, 399-407.
26. Baker H, Frank O, DeAngelis B, et al. (1980) Plasma tocopherol in man at various times after ingesting free or acetylated tocopherol. Nutr Rep Int 21, 531-536.

27. Fenning A, Harrison G, Rose'meyer R, et al. (2005) L-Arginine attenuates cardiovascular impairment in DOCA-salt hypertensive rats. Am J Physiol Heart Circ Physiol 289, H1408-H1416.

28. Rajasekaran D, Manoharan S, Silvan S, et al. (2012) Proapoptotic, anti-cell proliferative, anti-inflammatory and anti-angiogenic potential of carnosic acid during 7,12 dimethylbenz[a]anthracene-induced hamster buccal pouch carcinogenesis. Afr J Tradit Complement Altern Med 10, 102-112.

29. Katsumi H, Nishikawa M \& Hashida M (2007) Development of nitric oxide donors for the treatment of cardiovascular diseases. Cardiovasc Hematol Agents Med Chem 5, 204-208.

30. Boe AE, Eren M, Murphy SB, et al. (2013) Plasminogen activator inhibitor-1 antagonist TM5441 attenuates $\mathrm{N}^{\omega}$-nitroL-arginine methyl ester-induced hypertension and vascular senescence. Circulation 128, 2318-2324.

31. Yang HY, Yang SC, Chen ST, et al. (2008) Soy protein hydrolysate ameliorates cardiovascular remodeling in rats with L-NAME-induced hypertension. J Nutr Biochem 19, 833-839.

32. Ulker S, McKeown PP \& Bayraktutan U (2003) Vitamins reverse endothelial dysfunction through regulation of eNOS and $\mathrm{NAD}(\mathrm{P}) \mathrm{H}$ oxidase activities. Hypertension 41, 534-539.

33. Ndisang JF \& Chibbar R (2014) Heme oxygenase improves renal function by potentiating podocyte-associated proteins in $\mathrm{N}^{\omega}$-nitro-L-arginine-methyl ester (L-NAME)-induced hypertension. Am J Hypertens 28, 930-942.

34. Paulis L, Zicha J, Kunes J, et al. (2008) Regression of L-NAME-induced hypertension: the role of nitric oxide and endothelium-derived constricting factor. Hypertens Res 31, 793-803.

35. Dikalov SI \& Ungvari Z (2013) Role of mitochondrial oxidative stress in hypertension. Am J Physiol Heart Circ Physiol 305, H1417-H1427.

36. Rodrigo R, Libuy M, Feliú F, et al. (2013) Oxidative stress-related biomarkers in essential hypertension and ischemia-reperfusion myocardial damage. Dis Markers 35 , 773-790.

37. Senthil S, Veerappan RM, Ramakrishna Rao M, et al. (2004) Oxidative stress and antioxidants in patients with cardiogenic shock complicating acute myocardial infarction. Clin Chim Acta 348, 131-137.

38. Seifi B, Kadkhodaee M, Karimian SM, et al. (2010) Evaluation of renal oxidative stress in the development of DOCA-salt induced hypertension and its renal damage. Clin Exp Hypertens 32, 90-97.

39. Karthikeyan J \& Rani P (2003) Enzymatic and non-enzymatic antioxidants in selected Piper species. Indian J Exp Biol 41, $135-140$.

40. Abidi P, Afaq F, Arif JM, et al. (1999) Chrysotile-mediated imbalance in the glutathione redox system in the development of pulmonary injury. Toxicol Lett 106, 31-39.

41. Newaz MA \& Nawal NN (1999) Effect of gamma-tocotrienol on blood pressure, lipid peroxidation and total antioxidant status in spontaneously hypertensive rats (SHR). Clin Exp Hypertens 21, 1297-1313.

42. Hiremath $\mathrm{P}$, Bauer M, Aguirre AD, et al. (2014) Identifying early changes in myocardial microstructure in hypertensive heart disease. PLOS ONE 9, e97424.

43. Chatziantoniou C \& Dussaule JC (2005) Insights into the mechanisms of renal fibrosis: is it possible to achieve regression? Am J Physiol Renal Physiol 289, F227-F234. 
44. Olzinski AR, McCafferty TA, Zhao SQ, et al. (2005) Hypertensive target organ damage is attenuated by a p38 MAPK inhibitor: role of systemic blood pressure and endothelial protection. Cardiovasc Res 66, 170-178.

45. de Gasparo M, Hess P, Nuesslein-Hildesheim B, et al. (2000) Combination of non-hypotensive doses of valsartan and enalapril improves survival of spontaneously hypertensive rats with endothelial dysfunction. $J$ Renin Angiotensin Aldosterone Syst 1, 151-158.

46. Mattson DL, Kunert MP, Roman RJ, et al. (2005) Substitution of chromosome 1 ameliorates L-NAME hypertension and renal disease in the fawn-hooded hypertensive rat. Am J Physiol Renal Physiol 288, F1015-F1022.

47. Mulvany MJ, Baumbach GL, Aalkjaer C, et al. (1996) Vascular remodeling. Hypertension 28, 505-506.

48. Nadruz W (2015) Myocardial remodeling in hypertension. J Hum Hypertens 29, 1-6.

49. Díez J, Querejeta R, López B, et al. (2002) Losartan-dependent regression of myocardial fibrosis is associated with reduction of left ventricular chamber stiffness in hypertensive patients. Circulation 105, 2512-2517.

50. Manabe I, Shindo T \& Nagai R (2002) Gene expression in fibroblasts and fibrosis: involvement in cardiac hypertrophy. Circ Res 91, 1103-1113.

51. Mapanga RF, Rajamani U, Dlamini N, et al. (2002) Oleanolic acid: a novel cardioprotective agent that blunts hyperglycemia-induced contractile dysfunction. PLOS ONE 7, e47322.

52. Versari D, Daghini E, Virdis A, et al. (2009) Endotheliumdependent contractions and endothelial dysfunction in human hypertension. Br J Pharmacol 157, 527-536.

53. Török J (2008) Participation of nitric oxide in different models of experimental hypertension. Physiol Res 57, 813-825.

54. Chen B, Shi L, Yu X, et al. (2012) Differential effects of Rho-kinase inhibitor and angiotensin II type-1 receptor antagonist on the vascular function in hypertensive rats induced by chronic L-NAME treatment. Acta Pharm Sin B $\mathbf{2}$, 450-458.

55. Kung CF, Moreau P, Takase H, et al. (1995) L-NAME hypertension alters endothelial and smooth muscle function in rat aorta. Prevention by trandolapril and verapamil. Hypertension 26, 744-751.

56. Fan D, Takawale A, Lee J, et al. (2012) Cardiac fibroblasts, fibrosis and extracellular matrix remodeling in heart disease. Fibrogenesis Tissue Repair 5, 15.

57. Ammarguellat FZ, Gannon PO, Amiri F, et al. (2002) Fibrosis, matrix metalloproteinases, and inflammation in the heart of DOCA-salt hypertensive rats: role of ET(A) receptors. Hypertension 39, 679-684.

58. Chen H, Huang XN, Stewart AF, et al. (2004) Gene expression changes associated with fibronectin-induced cardiac myocyte hypertrophy. Physiol Genomics 18, 273-283. 